\title{
Potential of Copper Alloys using a Divertor Heat Sink in the Helical Reactor FFHR-d1 and their Brazing Properties with Tungsten Armor by using the Typical Candidate Filler Materials ${ }^{*)}$
}

\author{
Masayuki TOKITANI, Suguru MASUZAKI, Yutaka HIRAOKA ${ }^{1)}$, Hiroyuki NOTO, \\ Hitoshi TAMURA, Teruya TANAKA, Takeo MUROGA, Akio SAGARA and FFHR Design Group \\ National Institute for Fusion Science, 322-6 Oroshi-cho, Toki 509-5292, Japan \\ 1) Department of Applied Physics, Okayama University of Science, 1-1 Ridai-cho, Okayama 700-0005, Japan
}

(Received 25 November 2014 / Accepted 17 February 2015)

\begin{abstract}
A tungsten block is supposed to be used as a divertor armor material on the helical reactor FFHR-d1. On the other hand, material selection of the heat sink and bonding technique between armor and heat sink are currently under investigation. On the material selection, copper alloy has a large advantage for the thermal conductivity, but its material properties such as toughness and thermal conductivity, are dramatically decreased due to the neutron irradiation. However, from the assessment of the neutronics environment on the divertor region of the FFHR$\mathrm{d} 1$, copper alloys could be used for a heat sink especially at the outer divertor. In the ITER case, copper alloy $(\mathrm{CuCrZr})$ pipes are joined by a brazing technique with Nicuman37 filler material. This combination has not been optimized for the FFHR-d1, because the toughness of the $\mathrm{CuCrZr}$ at high temperature over $450^{\circ} \mathrm{C}$ is dramatically decreased with increasing the temperature. As such, another candidate is an oxide dispersion-strengthened copper alloy (ODS-Cu) such as GlidCop ${ }^{\circledR}$. For the bonding technique, a reliable brazing combination between "two kinds of copper alloys" and "three kinds of filler materials (MBF-20, BNi-6, Nicuman37)" were investigated from a viewpoint of mechanical strength. The most superior fracture strength among the three filler materials was BNi-6 with GlidCop ${ }^{\circledR}$.
\end{abstract}

(C) 2015 The Japan Society of Plasma Science and Nuclear Fusion Research

Keywords: copper alloy, tungsten, brazing, neutron irradiation

DOI: $10.1585 /$ pfr. 10.3405035

\section{Introduction}

The divertor armor material of the helical reactor is considering tungsten block because tungsten has large advantages for low hydrogen isotope retention and low sputtering yield. However, material selection of the heat sink and bonding technique between armor and heat sink is currently under investigation. Under heavy neutron irradiation environment in a fusion reactor, reduced activation ferritic/martensitic steel (RAFM), such as $\mathrm{F} 82 \mathrm{H}$, is one of the candidate materials for the divertor heat sink or the cooling pipe [1], because it has high robustness against a neutron irradiation. However, F82H would not be able to withstand the heat load of the FFHR-d1 divertor over $10 \mathrm{MW} / \mathrm{m}^{2}$, due to the high self-induced internal thermal stress, as discussed in Sec. 3.1.

Under such a condition, copper alloys with high thermal conductivity has a large advantage for the FFHR-d1 divertor. However, they cannot be acceptable under heavy neutron irradiation because the remarkable degradation of the material properties, such as toughness and thermal conductivity, occurs at a wide temperature range, as discussed

author's e-mail: tokitani.masayuki@LHD.nifs.ac.jp

*) This article is based on the presentation at the 24th International Toki Conference (ITC24). in Sec. 3.2 [2]. However, from the assessment of the neutronics environment at the divertor of the FFHR-d1 to date, copper alloys could be used for a heat sink especially at the outer divertor of the torus [3].

In the ITER case, a precipitation hardened copper alloy $(\mathrm{PH}-\mathrm{Cu})$ of $\mathrm{CuCrZr}$ pipes are supposed to be used, and be joined by a brazing technique with Nicuman 37 (Cu52.5\%, Mn38\%, Ni9.5\%) filler material to the tungsten armor [4]. This combination is not optimized for FFHR$\mathrm{d} 1$ because the toughness of the $\mathrm{CuCrZr}$ at a high temperature over $450^{\circ} \mathrm{C}$ is dramatically decreased by increasing the temperature. The operation temperature of the divertor heat sink in the FFHR-d1 is currently under discussion, but is hoped to be use at a high temperature range over $100^{\circ} \mathrm{C}$ to obtain a good efficiency of the energy conversion. Under such a situation, an oxide dispersion-strengthened copper alloy $(\mathrm{ODS}-\mathrm{Cu})$ such as GlidCop ${ }^{\circledR}\left(\mathrm{Cu}-0.3 \mathrm{wt} \% \mathrm{Al}_{2} \mathrm{O}_{3}\right)$ is another candidate copper alloy. If GlidCop ${ }^{\circledR}$ is selected for the FFHR-d1, the filler material of Nicuman37 might not be able to be used for maintaining a reliable brazing condition during an entire operation period.

In this paper, we first discuss the advantage of the copper alloys against the thermal heat loading compared with the $\mathrm{F} 82 \mathrm{H}$. We then briefly review mechanical properties of 
the two copper alloys $\mathrm{CuCrZr}$ and GlidCop ${ }^{\circledR}$ in high temperature range. Then, degradation of the material properties under neutron irradiation is reviewed and discussed. Next, reliable brazing combinations between "two kinds of copper alloys" and "three kinds of filler materials" are discussed based on the results of the brazing test of copper alloys to tungsten. Finally, the best combination of the copper alloys and brazing filler materials are summarized from these results and discussions.

\section{Structural Advantage of FFHR-d1 Divertor}

The intrinsic structure of the FFHR-d1 is similar to the Large Helical Device (LHD) [5]. While device size is four times larger than the LHD, the major radius $(\mathrm{R})$ is $R=15.6 \mathrm{~m}$ [6-8]. In the case of the heliotron type devices, the edge magnetic structure is more complicated than the tokamak devices, and an intrinsic divertor exists without additional coils [9]. Because of such characteristics, the total length of the divertor trace $\left(L_{\text {div }}\right)$ of the FFHR-d1 is $L_{\text {div }} \sim 900 \mathrm{~m}$ which is much longer than that of the same sized tokamak reactors, i.e., Slim-CS $(R=5.5)$ [10]. Consequently, the total area of the divertor strike point of the FFHR-d1 can be estimated to be $\sim 32 \mathrm{~m}^{2}$. These characteristic have a large advantage for distribution of the divertor heat flux.

The main fusion reaction is supposed to be the following equation.

$$
\mathrm{D}+\mathrm{T}={ }^{4} \mathrm{He}(3.52 \mathrm{MeV})+\mathrm{n}(14.06 \mathrm{MeV}) .
$$

If we assume the $33 \%$ of the power conversion efficiency for acquisition of a $1 \mathrm{GW}$ fusion power gain, the total fusion power output of the FFHR-d1 is required to be $\sim 3 \mathrm{GW}$ [6]. The $\alpha$ heating ratio can be estimated to be $3 \mathrm{GW}$ $\times 3.5 /(14+3.5) \approx 600 \mathrm{MW}$. If we assume that the radiation loss is $\sim 100 \mathrm{MW}$, the remaining $\alpha$ heating power of $500 \mathrm{MW}$ is absorbed by the divertor, an average heat flux is reached around $15.6 \mathrm{MW} / \mathrm{m}^{2}$. If the radiation loss is assumed to be $35 \%$ of the total $\alpha$ heating power, average heat flux is decreased to around $10 \mathrm{MW} / \mathrm{m}^{2}$. However, since the heat flux is not homogeneously distributed to the entire divertor strike point, the peaking heat flux could exceed $10 \mathrm{MW} / \mathrm{m}^{2}$.

\section{Potential of the Candidate Copper Alloys for FFHR-d1}

\subsection{Advantage of the copper alloy against the thermal heat loading}

The advantage of the copper alloys against the thermal heat loading is compared with F82H. Figure 1 (a) shows the temperature gradient between surface and back surface of a pure copper (Pure-Cu) and $\mathrm{F} 82 \mathrm{H}$ as a function of an input power. Input power from the divertor plasma in the FFHR-d1 is expected to exceed $10 \mathrm{MW} / \mathrm{m}^{2}$. In the
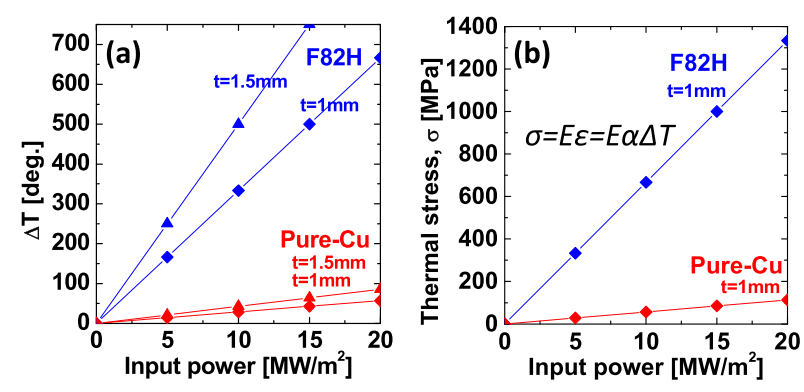

Fig. 1 (a) Temperature gradient as a function of an input power in different thickness of $\mathrm{F} 82 \mathrm{H}(30 \mathrm{~W} / \mathrm{m} \cdot \mathrm{K})$ and Pure-Cu $(320 \mathrm{~W} / \mathrm{m} \cdot \mathrm{K})$. (b) Induced internal thermal stress $(\sigma)$ as a function of an input power in the $1 \mathrm{~mm}$ thickness of $\mathrm{F} 82 \mathrm{H}$ and Pure-Cu. E: Young's modulus [Pa], $\alpha$ : Thermal expansion coefficient $\left[\mathrm{K}^{-1}\right]$.

case of Pure- $\mathrm{Cu}$, temperature gradient $(\Delta T)$ is below $50^{\circ} \mathrm{C}$ with a thickness of $1 \sim 1.5 \mathrm{~mm}$. In the case of $\mathrm{F} 82 \mathrm{H}, \Delta T$ is over $300^{\circ} \mathrm{C}$ and $500^{\circ} \mathrm{C}$ with a thickness of $1.0 \mathrm{~mm}$ and $1.5 \mathrm{~mm}$, respectively. Figure 1 (b) shows the induced internal thermal stress $(\sigma)$ in the Pure-Cu and $\mathrm{F} 82 \mathrm{H}$ as a function of an input power calculated by a simple equation which is shown in Fig. 1 (b), the $\Delta T$ was derived from Fig. 1 (a). This calculation is a very rough estimation, and took into account only the internal (whole) stress produced by its own thermal expansion on a fully restricted condition. High thermal stress of $\sim 600 \mathrm{MPa}$ is induced at $\sim 10 \mathrm{MW} / \mathrm{m}^{2}$ in the $1 \mathrm{~mm}$ thickness of the F82H. Since the yield strength of the $\mathrm{F} 82 \mathrm{H}$ is $\sim 500 \mathrm{MPa}$, this material cannot be used in this condition. On the other hand, internal thermal stress of Pure-Cu is $\sim 100 \mathrm{MPa}$ even at $\sim 20 \mathrm{MW} / \mathrm{m}^{2}$. This result indicates that copper and their alloys can be sufficiently used under $\sim 10 \mathrm{MW} / \mathrm{m}^{2}$ heat loading and have a large advantage for handling the high heat loading in the divertor.

\subsection{Degradation of the material properties under neutron irradiation}

As mentioned in section 1, the developed and assessed copper alloys for fusion use to date are mainly categorized as an ODS-Cu such as GlidCop ${ }^{\circledR}$ and a PH-Cu of $\mathrm{CuCrZr}$. We assessed these two alloys in this study. The GlidCop ${ }^{\circledR}$ is an $\mathrm{Al}_{2} \mathrm{O}_{3}$ dispersed copper, and it has superior high temperature strength over $300 \mathrm{MPa}$ even after the annealing up to about $1000^{\circ} \mathrm{C}$. However, since its manufacturing process is complicated through the special powder metallurgy (PM) processes, its cost is rather high. On the other hand, the manufacturing process of the $\mathrm{CuCrZr}$ has an advantage because it can be used as a casting. The thermal conductivity of both the GlidCop ${ }^{\circledR}$ and $\mathrm{CuCrZr}$ are almost the same as the Pure-Cu.

Determining the radiation threshold for using the copper alloy under neutron irradiation is difficult because not only energy spectrum and dose of the neutron but also material temperature are complicatedly related to changing 
Table 1 Typical threshold parameter of the GlidCop ${ }^{\circledR}$ and $\mathrm{CuCrZr}$ related with the radiation-induced hardening/softening $[2,11]$. The same parameters of Pure- $\mathrm{Cu}$ are also listed together for comparison.

\begin{tabular}{l|l|l|l|l|}
$\begin{array}{l}\text { Pure- } \mathrm{Cu} \\
\text { and } \\
\text { Cu alloys }\end{array}$ & $\begin{array}{l}\text { Yield strength at } \\
\text { room temperature }\end{array}$ & $\begin{array}{l}\text { Threshold temp. of } \\
\text { radiation induced } \\
\text { hardening/softening }\end{array}$ & $\begin{array}{l}\text { Radiation limit for } \\
\text { radiation induced } \\
\text { hardening }\end{array}$ & $\begin{array}{l}\text { Radiation limit for } \\
\text { radiation induced } \\
\text { softening }\end{array}$ \\
\hline Pure-Cu & $\sim 60 \mathrm{MPa}$ & --- & $\sim 0.1 \mathrm{dpa}$ & --- \\
\hline $\begin{array}{l}\mathrm{GlidCop} \\
(\mathrm{ODS}-\mathrm{Cu})\end{array}$ & $>400 \mathrm{MPa}$ & $\sim 300^{\circ} \mathrm{C}$ & $\begin{array}{l}\sim 0.2 \mathrm{dpa} \\
\text { (below } 300^{\circ} \mathrm{C} \text { ) }\end{array}$ & $\begin{array}{l}1 \sim 2 \mathrm{dpa} \\
\text { (slowly) }\end{array}$ \\
$\begin{array}{l}\mathrm{CuCrZr} \\
(\mathrm{PH}-\mathrm{Cu})\end{array}$ & $>400 \mathrm{MPa}$ & $\sim 280^{\circ} \mathrm{C}$ & $\begin{array}{l}\sim 0.2 \mathrm{dpa} \\
\text { (below } 280^{\circ} \mathrm{C} \text { ) }\end{array}$ & $\sim 1 \mathrm{dpa}$ \\
\end{tabular}

the material properties. The changeable material properties by neutron irradiation are (1) radiation-induced hardening/softening [2,11], (2) embrittlement by transmuted helium [12], (3) degradation of the thermal conductivity by transmutation products $[2,13]$, and (4) void swelling [2,14-16]. These material properties directly affect the mechanical properties. From the earlier studies, it was clarified that the lowest radiation limit above four properties was "(1) radiation-induced hardening/softening" [2, 11-16]. Typical threshold parameter related with the radiation-induced hardening/softening was summarized in Table 1. The acceptable dose level of the radiation-induced hardening/softening in both copper alloys is $0.2 \sim 1 \mathrm{dpa}$, and it has temperature dependence. Its threshold temperature of $\mathrm{GlidCop}^{\circledR}$ and $\mathrm{CuCrZr}$ are $\sim 300^{\circ} \mathrm{C}$ and $\sim 280^{\circ} \mathrm{C}$, respectively. The hardening and softening occur below and above these temperatures, respectively.

This property directly affects the maintaining of the toughness of the heat sink materials. In the case of the ODS- $\mathrm{Cu}$ and $\mathrm{PH}-\mathrm{Cu}$, dispersed or precipitated particles into the matrix should act as an obstacle against the dislocation. However, in the case of the radiation-induced hardening, the saturated radiation-induced dislocation loops and stacking fault tetrahedras (SFTs) heterogeneously prevent a motion of the dislocations, and thereby the ability of the homogenous elongation is lost. Conversely, in the radiation-induced softening, particles precipitated or dispersed into the matrix are dissociated by neutron irradiation. Otherwise, original dislocations and voids are terminated due to the radiation induced recrystallization. Consequently, the obstacles for the movable dislocations disappear and thereby, materials are softened [11].

From the above information, the best material for the heat sink of the FFHR-d1 could be the GlidCop ${ }^{\circledR}$, and its temperature should be kept at $300^{\circ} \mathrm{C}$ without any temperature frustration during operation period.

\section{Brazing Test of Copper Alloys to Tungsten}

\subsection{Experimental procedures}

The size of the copper alloys and tungsten for brazing tests are $30 \times 30 \times 38 \mathrm{~mm}^{3}$ and $30 \times 30 \times 18 \mathrm{~mm}^{3}$, respec-
Table 2 Chemical composition of the selected filler materials used in this study.

\begin{tabular}{|l|c|c|c|c|c|c|c|c|c|c|}
\hline Filler materials & $\begin{array}{l}\text { Solid phase } \\
\text { temperature }\end{array}$ & $\begin{array}{l}\text { Liquid phase } \\
\text { temperature }\end{array}$ & $\mathrm{Cr}$ & $\mathrm{Cu}$ & $\mathrm{Mn}$ & $\mathrm{Ni}$ & $\mathrm{P}$ & $\mathrm{Si}$ & $\mathrm{Fe}$ & $\mathrm{B}$ \\
\hline $\mathrm{MBF}-20$ & $969^{\circ} \mathrm{C}$ & $1024^{\circ} \mathrm{C}$ & 7 & & & bal. & & 4 & 3 & 3 \\
\hline BNi-6 & $875^{\circ} \mathrm{C}$ & $875^{\circ} \mathrm{C}$ & & & & bal. & 11 & & & \\
\hline Nicuman37 & $880^{\circ} \mathrm{C}$ & $925^{\circ} \mathrm{C}$ & & 52.5 & 38 & 9.5 & & & & \\
\hline
\end{tabular}

(a) MBF-20

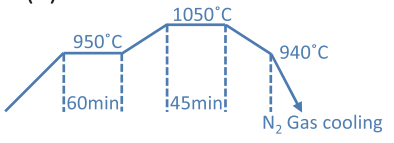

(b) BNi-6, Nicuman37

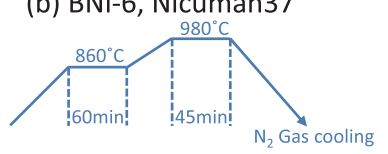

Fig. 2 Procedures of the heat treatment of (a) MBF-20 and (b) BNi-6 and Nicuman37 filler materials.

tively. Each $30 \times 30 \mathrm{~mm}^{2}$ plane was used as a brazing surface. The selected copper alloys for this experiment are the $\mathrm{CuCrZr}$ and the GlidCop ${ }^{\circledR}$. For the case of the GlidCop ${ }^{\circledR}$, since the grains were elongated along the cold working direction, two kinds of block were extracted from the ingot. The first ones are the grain that were elongated perpendicular $(\perp)$ to a brazing surface; the others were elongated parallel (//) to a brazing surface. The selected filler materials and their chemical compositions to be tested are summarized in Table 2. Brazing procedures were carried out in the high-vacuum furnace in the Metal Technology Co. Ltd. Since the temperatures of the solid and the liquid phases differ by each filler material, two types of heat treatment procedures were selected, as shown in Fig. 2.

After the heat treatment procedures, the brazed blocks were fabricated to be the small size specimens with the size of $36 \times 5 \times 1.5 \mathrm{~mm}^{3}$. Then, a three point bending test was carried out by using the SHIMADZU Autograph at Okayama University of Science.

\subsection{Results and discussions}

Figure 3 shows the stress-strain curves of the three point bending test for the nine combination patterns of the copper alloys and the filler materials. Since the five specimens were prepared for one combination, there are five stress-strain curves in one combination. In the case of the No. 2 and 4, specimens were not able to be fabricated as a small size specimens for the bending test because of the fracture of the tungsten just beneath the brazing. This might have been caused by any internal stress induced in the tungsten blocks due to differences of the thermal expansion coefficient between tungsten and copper alloys. While in the case of the No. 8 , the brazing completely failed.

Therefore, the details of the discussions regarding the brazing strength have to be conducted using the remaining six specimens. In the case of MBF-20, fracture stress was quite low at around $50 \mathrm{MPa}$ and $100 \mathrm{MPa}$ for the $\mathrm{CuCrZr}$ and GlidCop ${ }^{\circledR}$, respectively. This filler ma- 

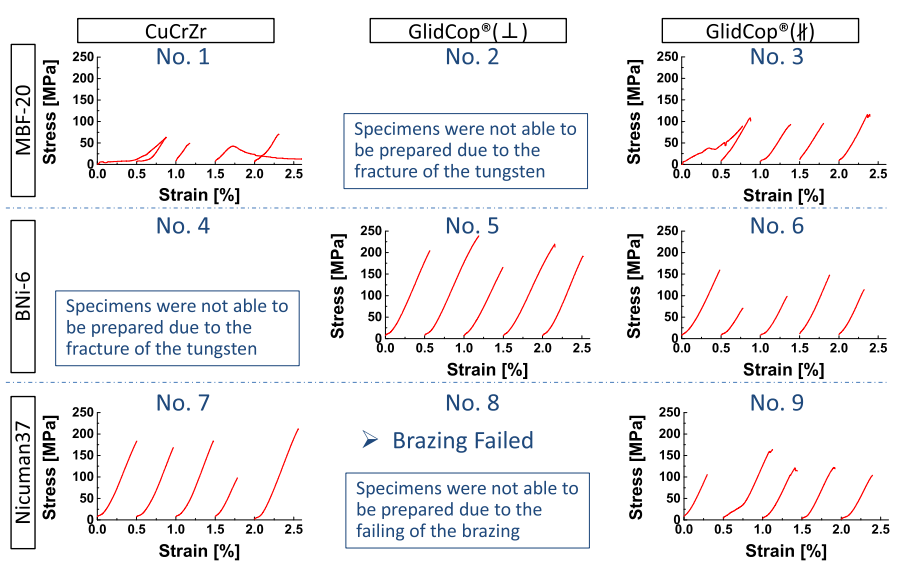

Fig. 3 Stress-strain curve of the three point bending test for the nine combination patterns of the copper alloys and the filler materials.

terial seems to be bad for the brazing. In the case of the Nicuman37, it has an interesting property. Although the fracture stress reached to $\sim 200 \mathrm{MPa}$ in the $\mathrm{CuCrZr}$, it decreased to $\sim 150 \mathrm{MPa}$, or the brazing failed completely in the GlidCop ${ }^{\circledR}$. This seems to indicate that some chemical component, i.e., $\mathrm{Cr}$ in the $\mathrm{CuCrZr}$ might have acted as the effective intermediate object for the good brazing. Therefore, Nicuman37 will not be able to be used with GlidCop $^{\circledR}$. The most superior fracture strength among the three filler materials was BNi-6 with GlidCop ${ }^{\circledR}(\perp)$. The effects of the elongating direction, between perpendicular $(\perp)$ and parallel $(/ /)$ to a brazing surface against the brazing surface could not be identified in this experiment.

\section{Summary}

According to the current design of the FFHR-d1 and its divertor characteristics, the total area of the divertor strike point can be estimated to be $\sim 32 \mathrm{~m}^{2}$. This characteristic provides great advantages for distribution of the divertor heat flux. As such, the average heat flux is estimated to be around $10 \mathrm{MW} / \mathrm{m}^{2}$.

The F82H cannot withstand under $\sim 10 \mathrm{MW} / \mathrm{m}^{2}$ heat loading because of its induced internal thermal stress. On the other hand, a copper and their alloys can be sufficiently used under the same heat loading.

From the assessment of the neutronics environment at the divertor of the FFHR-d1 to date, copper alloys could be used for a heat sink especially at the outer divertor [3]. The candidate copper alloys for fusion use to date are mainly considered to be GlidCop ${ }^{\circledR}$ and $\mathrm{CuCrZr}$. The changeable material properties by neutron irradiation were summarized in four properties. The current best material for the heat sink of the FFHR-d1 could be considered to be the GlidCop ${ }^{\circledR}$, and its temperature should be kept at $300^{\circ} \mathrm{C}$ without any temperature fluctuation during the operation period.

Reliable brazing combinations between "two kinds of copper alloys" and "three kinds of filler materials" were examined. The results indicate that the Nicuman37 will not be able to be used with GlidCop ${ }^{\circledR}$, and the most superior fracture strength among three filler materials was BNi-6 with GlidCop ${ }^{\circledR}$.

According to the brazing properties, high temperature strength, and neutron irradiation characteristics of the copper alloys, the combination of BNi- 6 and the GlidCop ${ }^{\circledR}$ is the current best choice for the FFHR-d1 divertor structure, and the temperature of the GlidCop ${ }^{\circledR}$ should be kept at $300^{\circ} \mathrm{C}$ without changing. The brazing strength of the BNi- 6 at elevated temperature such as $300^{\circ} \mathrm{C}$ will be investigated. Then, more reliable materials, brazing technique, and their combinations will be studied towards the final design of the divertor structure of the FFHR-d1.

\section{Acknowledgements}

This study was conducted as a Fusion Energy Research Project (FERP) in National Institute for Fusion Science (NIFS). The authors would like to thank the Metal Technology Co. Ltd. for brazing.

[1] S. Suzuki et al., Fusion Eng. Des. 81, 93 (2006).

[2] S.J. Zinkle and S.A. Fabritsiev, DOE/ER-0313/16 (1994).

[3] T. Tanaka et al., Fusion Eng. Des. 89, 1939 (2014).

[4] S. Suzuki et al., J. Plasma Fusion Res. 87, No.9, 607 (2011).

[5] A. Komori et al., Fusion Sci. Technol. 58, 1 (2010).

[6] A. Sagara et al., Fusion Eng. Des. 87, 594 (2012).

[7] T. Goto et al., Plasma Fusion Res. 7, 2405084 (2012).

[8] J. Miyazawa et al., Nucl. Fusion 52, 123007 (2012).

[9] S. Masuzaki et al., Nucl. Fusion 42, 750 (2002).

[10] K. Tobita et al., Fusion Eng. Des. 81, 1151 (2006).

[11] B.N. Sing et al., J. Nucl. Mater. 238, 244 (1996).

[12] S.A. Fabritsiev et al., Fusion Eng. Des. 36, 505 (1997).

[13] S. Ishino et al., J. Nucl. Mater. 283-287, 215 (2000).

[14] F.A. Garner et al., J. Nucl. Mater. 191-194, 386 (1992).

[15] D.J. Edwards et al., J. Nucl. Mater. 191-194, 416 (1992).

[16] T. Muroga et al., J. Nucl. Mater. 258-263, 955 (1998). 